establishment in 1951 of a seprate Ministry in the Union Government for Natural Resources and Scientific Research, with Sir S. S. Bhatnagar as its first secretary. Imperial Chemical Industries (India), Ltd., has given Rs. 336,000 for the award of research fellowships in physics, chemistry and biology for the next five years. Dr. Hora also directed attention to the fact that the Institute was meeting in its own building in Delhi, a building not yet complete, but one projected to house the Institute after it had enjoyed the hospitality of the University of Delhi since its transference to Delhi from Calcutta in 1945 .

\section{State Economic Areas in the United States}

To meet an increasing desire for more information about geographical areas of specialization, the United States Bureau of the Census has adopted new functional groupings which have been named 'State Economic Areas'. These new groupings, which are a feature of the 1950 Censuses of Agriculture, Popula. tion and Housing, are fully described by Donald $J$. Bogue in a publication of the Bureau of the Census, United States Department of Commerce, entitled "State Economic Areas. A Description of the Procedure used in making a Functional Grouping of the Counties of the United States" (pp. 96 ; Washington, D.C. : Govt. Printing Office, 1951; 1 dollar). A useful outline map is included which sets out the boundaries of the 501 State Economic Areas which have been delimited; each area on this map being marked by a symbol which will be used in identifying all statistics for that area in Census publications. The areas are relatively homogeneous subdivisions of States which show significant characteristics distinguishing them from adjoining areas. In determining them, demographic, climatic, physiographical and cultural factors have been taken into account as well as industrial and commercial activities. The name, State Economic Areas, has been adopted in order to convey the implication that each State has been divided into its principal units and that within each unit a distinctive economy prevails ; the term economy being used in its broadest sense as the total adjustment which the population of an area has made to a particular combination of natural resources and other environmental factors.

\section{Anthropological Studies of the Gusii Tribe of East Africa}

Dr. Philip Mayer, who acted as Kenya Government sociologist during the period 1946-50, is the author of "Two Studies in Applied Anthropology in Kenya" (Colonial Research Studies No. 3. Pp. 33 ; London: H.M.S.O., 1951 ; 2s. 6d. net), which deal with some investigations in primitive economics made during this period. The first is an examination of an indigenous co-operative association for farm work, and the second describos various measures adopted by the local African councils to control inflation of bride wealth. Both refer to the Gusii tribe. The two studies are interesting in illustrating how a 'chiefless' society which was notoriously unable to unite for political purposes is able to combine for economic needs; and they suggest that in the introduction of rural development schemes which are primarily economic rather than political in their objectives, the local-government administration would do well to discover and to use existing economic groupings rather than seek to work through the existing local-government machinery of chiefs and native councils. District officers in other areas of Central and East Africa should find these two reports both interesting and useful. Mr. A. Phillips, reader in Colonial law in the London School of Economics and Political Science, contributes a brief introduction.

\section{Radio Stars in the Northern Hemisphere}

A PAPER by M. Ryle, F. G. Smith and B. Elsmore (Mon. Not. Roy. Astro. Soc., 110, 6; 1950), entitled "A Preliminary Survey of the Radio Stars in the Northern Hemisphere", gives the results of the observations made at Cambridge since May 1948 of fifty radio stars in the northern hemisphere. The survey was made on a wave-length of $3.7 \mathrm{~m}$., and the stars ranged between magnitudes 3.9 and $-3 \cdot 4$. A short description is given of the spaced-aerial interferometer with an aperture of $110 \lambda$ and of the method employed for its use. The accuracy of determination of the position of a radio star depends on the intensity of the source, and the two most intense ones, in the constellations of Cygnus and Cassiopeia, can be located with an accuracy of about $3^{\prime}$ of arc, but most of them cannot be located with an accuracy of more than a degree of arc. Table 1 of the paper gives the co-ordinates, intensities and apparent magnitudes of the fifty stars investigated; the zero of the magnitude scale was arbitrarily chosen as corresponding to an intensity of $10^{-23} \mathrm{~W}$. $\mathrm{m}^{-2}$ (c./s.) $)^{-1}$. There exists the formidable problem of distinguishing between the radiation from an individual source and the general background radiation from the galaxy, but Kyle has shown that the presence of a large number of radio stars distributed throughout the galaxy would account for the general background radiation from it. At present it is possible to resolve only those sources that are nearest, owing to the poor resolving-power of the apparatus. The radio stars discovered have so far shown no detectable concentration in the galactic plane, and from this it is concluded that they must be outside the galaxy, or, if they are within it, they must be at distances small compared with the dimensions of the galaxy. It is believed that most radio stars are situated within the galaxy with an average population comparable with that of visual stars. Attempts to identify radio stars with various types of diffuse body within the galaxy and with planetary nebulæ and star clusters have not been successful, and at present the only conclusion is that they are a hitherto unobserved type of diffuse body, in which a very intense radiation is associated with a very small visual intensity.

\section{Measurement in Medicine}

IN an introductory chapter to "Measurement in Medicine" (Brit. Med. Bull., 7, No. 4, Part 1 ; 1951), Sir Henry Dale refers to "the recent and most welcome weakening of the attitude of critical aloofness which formerly prevailed between the experimental research workers in the laboratories and the clinical observers in the hospital wards". There is, he says, in the articles of this publication plentiful evidence of this new sense of sharing in the advance of medical knowledge. The subject headings of these articles (and authors) are as follows: the history of the quantitative approach in medicine (Dr. E. Ashworth Underwood); the measurement of normality (Dr. P. L. McKinlay); the clinical trial (Prof. A. Bradford Hill); biological standards and the measurement of therapeutic activity (Dr. A. A. Miles); biological assay (Dr. A. Finney); co mposition of the body 